\title{
Dose-dense Paclitaxel- and Carboplatin-based Neoadjuvant Chemotherapy Followed by Surgery or Concurrent Chemo- radiotherapy in Cervical Cancer: a Preliminary Analysis
}

\author{
ANGIOLO GADDUCCI ${ }^{1}$, CECILIA BARSOTTI ${ }^{1}$, CONCETTA LALISCIA $^{2}$, STEFANIA COSIO $^{1}$, \\ ANTONIO FANUCCHI ${ }^{1}$, ROBERTA TANA ${ }^{1}$ and MARIA GRAZIA FABRINI ${ }^{2}$ \\ ${ }^{1}$ Department of Clinical and Experimental Medicine, \\ Division of Gynecology and Obstetrics, University of Pisa, Pisa, Italy; \\ ${ }^{2}$ Department of Translation Medicine, Division of Radiation Oncology, University of Pisa, Pisa, Italy
}

\begin{abstract}
Aim: To assess preliminary results with dosedense neoadjuvant chemotherapy (NACT) prior to surgery or concurrent chemo-radiotherapy (CCRT) in cervical cancer. Patients and Methods: Thirty patients received weekly paclitaxel $\left(80 \mathrm{mg} / \mathrm{m}^{2}\right)$ plus carboplatin (AUC2) for 6 cycles followed by radical hysterectomy in 16 (stage $I b_{2}-I I b$ ), conisation in one (stage Ib1), and CCRT in 13 (stage Ib $\mathrm{I}^{-}$ $I I b$ ). Median follow-up of survivors was 12 months (range= 3-22). Results: Among the surgically treated patients, clinical overall response rate $(R R)$ was $82.3 \%$, optimal pathological $R R$ was $17.6 \%$, and suboptimal pathological RR with intracervical residual disease was $41.2 \%$. Only one patient relapsed. Among the CCRT treated patients, partial RR after NACT was $76.9 \%$ and complete RR after CCRT was $58.3 \%$. However, $42.8 \%$ of complete responders recurred. Toxicity was acceptable. Conclusion: Dose-dense NACT seems to achieve promising RRs with manageable toxicity in cervical cancer. Investigation on larger series with longer follow-up is warranted.
\end{abstract}

Concurrent chemo-radiotherapy (CCRT) plus brachytherapy is the standard of care for locally advanced cervical cancer (LACC) and recent meta-analysis of randomized trials has confirmed that this therapeutic approach significantly improves the clinical outcome of patients compared to definitive radiotherapy (RT) alone (1-6). However, about 30-

Correspondence to: Angiolo Gadducci, Department of Clinical and Experimental, Medicine, Division of Gynecology and Obstetrics, University of Pisa, Via Roma 56, Pisa, 56127, Italy. Tel: +39 50992609, Fax: +39 50553410, e-mail: a.gadducci@med.unipi.it

Key Words: Cervical cancer, dose-dense neoadjuvant chemotherapy, carboplatin, paclitaxel, radical hysterectomy, concurrent chemoradiotherapy, recurrence.
$40 \%$ of patients with LACC fail to achieve a complete response to CCRT (7). In an attempt to improve their outcome, several approaches have been investigated, such as the use of neoadjuvant chemotherapy (NACT) before definitive RT, the use of adjuvant chemotherapy after CCRT, and the use of NACT followed by radical hysterectomy. The meta-analysis of 18 trials that compared NACT followed by definitive RT versus the same RT alone revealed a trend to a better overall survival (OS) for NACT arm when chemotherapy cycle length was $\leq 14$ days (Hazard Ratio $(\mathrm{HR})=0.83$, 95\% Confidence Interval $(\mathrm{CI})=0.69-1.00)$ or CDDP dose intensity was $\geq 25 \mathrm{mg} / \mathrm{m}^{2} /$ week (HR $=0.91,95 \%$ $\mathrm{CI}=0.78-1.05$ ) (8). Conversely, trials using cycle lengths longer than 14 days $(\mathrm{HR}=1.25,95 \% \mathrm{CI}=1.07-1.46)$ or $\mathrm{CDDP}$ dose intensity $<25 \mathrm{mg} / \mathrm{m}^{2} /$ week $(\mathrm{HR}=1.35,95 \% \mathrm{CI}=1.11$ 1.14) detected a detrimental effect of NACT. Few randomized trials seem to show a positive impact of adjuvant chemotherapy after CCRT $(4,9-11)$. This adjuvant treatment deserves to be further investigated, especially in patients with large tumor size, positive lymph nodes, and stage IIIIVA disease (7).

NACT followed by radical hysterectomy has achieved satisfactory results in cervical cancer, with tumor size reduction and down-staging, increased operability rate with free surgical margins, decreased incidence of lymph node and parametrial involvement, and better control of distant metastases (12-30). The meta-analyses of randomized trials showed that NACT followed by radical hysterectomy significantly improved progression-free survival (PFS) and OS compared to primary radical hysterectomy (31), and that NACT followed by radical hysterectomy was associated with a significantly better PFS and OS compared to definitive RT (8). Different CDDP-based regimens have been used in the NACT setting. The combination of ifosfamide, paclitaxel (TAX) and CDDP has obtained the highest optimal pathological response rates, associated with non-negligible 
hematologic toxicity and neurosensory symptoms $(15,21,26)$. A Japanese randomized phase III trial, enrolling 253 patients with metastatic or recurrent cervical cancer, found that TAX plus carboplatin (CBDCA) every 3 weeks [q21] was not inferior to TAX plus CCDP q21 in terms of OS, and it showed a lower incidence of grade 4 neutropenia, grade 3-4 febrile neutropenia, creatinine elevation and nausea/ vomiting (32). The combination of TAX plus CBDCA has been found to be an active regimen with acceptable toxicity also in the NACT setting $(33,34)$. Recently, some authors have investigated the feasibility and the clinical activity of a dose-dense NACT with weekly TAX plus CBDCA before radical hysterectomy or definitive CCRT in LACC $(28,35-37)$.

The purpose of this retrospective study was to assess the preliminary results of our experience with the use of dosedense NACT in this clinical setting.

\section{Materials and Methods}

This retrospective study was conducted on 30 patients with untreated cervical squamous cell carcinoma or adenocarcinoma that underwent dose-dense CBDCA- and TAX-based NACT followed by surgery or definitive CCRT after assessment of the multidisciplinary committee of gynecologic oncology of the azienda ospedaliera universitaria pisana (AOUP) between February 2015 and July 2016. Pre-treatment evaluation included history, physical examination, vaginal-pelvic examination, colposcopy, biopsy, complete blood analysis, chest X-ray, abdominal-pelvic computed tomography (CT) scan and/or Magnetic Resonance Imaging (MRI). Cystoscopy and/or proctoscopy wereperformed if there was a clinical and/ or radiological suspicion of bladder or rectal involvement. Further investigations werecarried out when indicated.

The clinical staging wasperformed according to the system adopted by FIGO.

Twenty-nine patients had FIGO stage $\mathrm{Ib}_{2}$-IV disease. NACT followed by radical hysterectomy was the common treatment strategy for patients with FIGO stage $\mathrm{Ib}_{2}$-IIa-IIb "early" (limited parametrial involvement) cervical carcinoma, whereas CCRT plus brachytherapy was the standard therapy for those with stage IIb "late" (extended parametrial involvement)-III-IVa disease.

Post-NACT treatment consisted of type II-III radical hysterectomy with pelvic lymphadenectomy in 16 patients and definitive CCRT in 13 patients. One patient with FIGO stage $\mathrm{Ib}_{1}$ adenocarcinoma underwent laparoscopic pelvic lymphadenectomy (with histologically negative nodes), followed by NACT and then conisation to spare fertility.

Dose-dense NACT consisted of TAX $\left(80 \mathrm{mg} / \mathrm{m}^{2}\right)$ plus CBDCA AUC 2 (area under the time-concentration curve of $2 \mathrm{mg} \times \mathrm{min} / \mathrm{ml}$ ) every week for 6 cycles. Physical and vaginal-pelvic examination and abdominal-pelvic CT scan and/or MRI were repeated 2-3 weeks after the completion of NACT.

Response to NACT was determined using the response evaluation criteria in solid tumors (RECIST) version 1.1 (38). Adverse events were evaluated according to the common terminology criteria for adverse events (CTCAE) Version 4.0 (Published: May 28, 2009 (v4.03: June 14, 2010).

Pathological responses of the patients who underwent surgery were assessed as reported in a previous paper (27). Complete response was defined as the complete disappearance of the tumor in the cervix with negative nodes; optimal partial response was defined as persistent residual disease with $<3 \mathrm{~mm}$ stromal invasion including in situ carcinoma on the surgical specimen and negative nodes; and suboptimal partial response consisted of persistent residual disease with $>3 \mathrm{~mm}$ stromal invasion on the surgical specimen and negative nodes (intra-cervical residual disease), or positive nodes with positive or negative parametria and/or surgical margins (extracervical residual disease with positive nodes), or positive parametria and/or surgical margins with negative nodes (extra-cervical residual disease with negative nodes). Overall, optimal response rate was the sum of complete and optimal partial response rates. Post-operative management was individually established on the basis of histological findings on surgical specimen, patient age and general conditions, after an exhaustive discussion with the patient herself by the multidisciplinary committee of gynecologic oncology.

The patients scheduled for definitive CCRT received external beam RT 50.4 Gy (in 25-28 fractions) concurrent with CDDP $40 \mathrm{mg} / \mathrm{m}^{2}$ weekly plus intracavitary brachytherapy. External RT was performed with a $15 \mathrm{MV}$ beam and a four-field conformal technique (gantry angles at $0^{\circ}, 90^{\circ}, 180^{\circ}$ and $270^{\circ}$ ) or with Volumetric Modulated Arc Therapy (VMAT) using $6 \mathrm{MV}$ beam. The pelvic target volume was outlined on a CT scan. When common iliac or para-aortic node involvement was detected on CT scan, the para-aortic space was included into the planned volume (45 Gy). Subsequently, a high-dose rate (HDR) brachytherapy was delivered as a boost with a three-way Fletcher-Williamson applicator set (Nucletron B.V., Veenendaal, Netherlands). The prescribed dose to the high-risk target volume was 21-28 Gy in 3-5 fractions (39). Rectal and bladder doses were estimated from dose volume histograms on CT-based plans.

Physical and vaginal-pelvic examination and abdominal-pelvic CT scan were repeated 8 to 12 weeks after the completion of RT.

Radiation induced toxicities were scored according to Radiation Therapy Oncology Group [RTOG]/European Organization for Research and Treatment of Cancer (EORTC) criteria (40).

The patients were periodically followed-up with clinical and radiological examinations until they died or until January 2017. The median follow-up of survivors was 12 months (range: 3-22 months).

The statistical package SAS, (Release 6.7, SAS institute, Cary, NC, USA), was used for computations.

\section{Results}

Patient characteristics. Patient characteristics at diagnosis are shown in Table I.

One patient with diagnosis of adenocarcinoma at pretreatment biopsy was found to have a mixed tumor consisting of both adenocarcinoma and high-grade neuroendocrine tumor of small cell type (SCNEC) at the definitive histological examination of hysterectomy specimen.

Patients treated with definitive CCRT had higher tumor stage and greater tumor size than those who underwent surgery. All the 6 patients with stage IIIb-IV disease received definitive CCRT after NACT, whereas all the 7 patients with stage $\mathrm{Ib}_{2}$ disease underwent radical hysterectomy.

Clinical outcome of the patients that underwent surgery. Clinical response to NACT was complete in 6 and partial in 
8 of the 17 patients who underwent surgery, with an overall response rate of $82.3 \%$. Three patients had stable disease.

Pathological response was complete in 2 and optimal partial in 1 , with an overall optimal response rate of $17.6 \%$, and suboptimal partial in $11(64.7 \%)$. Three patients had no response. One of the pathologically complete responders was the patient with stage Ib1 disease who underwent conisation.

As for suboptimal responders, $7(41.2 \%)$ had intra-cervical residual disease $\left(\mathrm{ypT}_{1} \mathrm{a}_{2}\right.$ with negative $\mathrm{LVSI}=1 ; \mathrm{ypT}_{1} \mathrm{~b}_{1}$ with negative $\mathrm{LVSI}=2, \mathrm{ypT}_{1} \mathrm{~b}_{1}$ with positive $\left.\mathrm{LVSI}=4\right), 2(11.8 \%)$ had extra-cervical residual disease with negative nodes, and $2(11.8 \%)$ had extra-cervical residual disease with positive nodes. Overall, histologically positive nodes, positive parametria and positive surgical margins were found in 2 $(12.5 \%), 3(18.7 \%)$ and $1(6.2 \%)$, of the 16 patients who underwent radical hysterectomy, respectively.

The two pathologically complete responders and the patient with intra-cervical residual $\mathrm{ypT}_{1} \mathrm{a}_{2}$ disease received no adjuvant treatment. The patient with optimal partial response is currently undergoing adjuvant chemotherapy with TAX (175 mg/m²) plus CBDCA (AUC5) q21.

Of the 6 patients with intra-cervical residual $\mathrm{ypT}_{1} \mathrm{~b}_{1}$ disease, 5 underwent adjuvant CCRT (followed by brachytherapy in one case because of isthmus involvement) and one received adjuvant external RT without concurrent CDDP. Of the 7 patients with extra-cervical residual disease or no response on surgical specimen, 6 underwent adjuvant CCRT (followed by brachytherapy in 3 cases). The remaining patient with a diagnosis of mixed adenocarcinoma and SCNEC on hysterectomy specimen received adjuvant chemotherapy with CDDP $\left(80 \mathrm{mg} / \mathrm{m}^{2}\right.$ day 1$)$ plus etoposide (100 mg/m² day $1-3) \mathrm{q} 21$.

Only one $(5.9 \%)$ of the 17 patients who underwent surgery developed local and distant recurrence (peritoneum and bone) 9 months after the first cycle of NACT. The other 16 patients are alive with no clinical evidence of disease (NED) after a median of 12 months (range=3-22 months) from the first cycle of NACT.

Clinical outcome of the patients who underwent definitive CCRT. Ten patients $(76.9 \%)$ had a partial response and 3 had stable disease after NACT. One patient stopped CCRT early, at a total RT dose of 3,600 cGy, because of pulmonary embolism and aspergillosis. She developed tumor progression in pelvis, aortic nodes and bone 6 months after starting NACT and died of disease 4 months later. Three patients, unfit to brachytherapy for vaginal stenosis, received stereotactic boost (15-20 Gy) on the high-risk target volume after CCRT.

The clinical and radiological evaluation detected complete response in $7(58.3 \%)$, partial response in $4(33.3 \%)$, and progressive disease in one $(8.3 \%)$ of the 12 patients that completed the scheduled treatment.
Table I. Patients' characteristics.

\begin{tabular}{|c|c|c|}
\hline & \multicolumn{2}{|c|}{ Post NACT treatment } \\
\hline & Surgery & CCRT \\
\hline Median age & $\begin{array}{c}50 \text { years } \\
(34-70 \text { years })\end{array}$ & $\begin{array}{c}55 \text { years } \\
\text { (35-63 years) }\end{array}$ \\
\hline \multicolumn{3}{|l|}{ FIGO stage } \\
\hline $\mathrm{Ib}_{1}$ & 1 & 0 \\
\hline $\mathrm{Ib}_{2}$ & 7 & 0 \\
\hline $\mathrm{IIa}$ & 2 & 1 \\
\hline IIb & 7 & 6 \\
\hline IIIb & 0 & 3 \\
\hline IVa & 0 & 3 \\
\hline \multicolumn{3}{|l|}{ Histological type } \\
\hline Squamous cell & 10 & 10 \\
\hline Adenocarcinoma & 5 & 3 \\
\hline Squamous + clear cell & 1 & 0 \\
\hline Adenocarcinoma + SCNEC & 1 & 0 \\
\hline \multicolumn{3}{|l|}{ Tumour grade } \\
\hline $\mathrm{G}_{1-2}$ & 3 & 5 \\
\hline $\mathrm{G}_{3}$ & 14 & 8 \\
\hline \multicolumn{3}{|l|}{ Tumour size } \\
\hline$<5 \mathrm{~cm}$ & 16 & 1 \\
\hline$>5 \mathrm{~cm}$ & 5 & 8 \\
\hline
\end{tabular}

NACT: Neoadjuvant chemotherapy; CCRT: concurrent chemoradiotherapy; SCNEC: high-grade neuroendocrine tumor of small cell type; G1: well differentiated; G2: moderately differentiated; G3: poorly differentiated.

The clinical outcome of 7 complete responders was as follows: 3 patients $(42.8 \%)$ were alive with NED 11 months, 13 months, and 20 months, respectively, after the first cycle of NACT; one patient $(14.3 \%)$ died of intercurrent gastric cancer 16 months after starting NACT with no clinical or radiological evidence of recurrent cervical cancer; and 3 patients $(42.8 \%)$ developed recurrent disease after 10 months (aortic nodes), 9 months (pelvis and aortic nodes) and 15 months (pelvis), respectively, after the first cycle of NACT. All 3 patients died of disease 7 months, 8 months, and 7 months later, respectively.

Of the 4 partial responders, 2 are still alive with disease 5 and 14 months after the first cycle of NACT, respectively, and the other 2 died of disease after 13 and 19 months, respectively. The patient with progressive disease is still undergoing palliative second-line chemotherapy 11 months after the first cycle of NACT.

Toxicity. Overall, 27 of the 30 patients $(90.0 \%)$ completed all six cycles of weekly NACT. TAX dose was reduced from 80 $\mathrm{mg} / \mathrm{m}^{2}$ to $60 \mathrm{mg} / \mathrm{m}^{2}$ in one patient after the first cycle due to increased serum bilirubin levels. Three patients stopped NACT after the fifth cycle because of persistent grade $(\mathrm{G})$ 3-4 neutropenia (n. 2) and pneumonia (n.1). 
Table II. Toxicity during neo-adjuvant chemotherapy (a) and during concurrent chemo-radiotherapy (b).

(a)

\begin{tabular}{|c|c|}
\hline Toxicities & NACT (30 pts) \\
\hline \multicolumn{2}{|c|}{ Leukopenia } \\
\hline $\mathrm{G} 1$ & $7(23.3 \%)$ \\
\hline $\mathrm{G} 2$ & $7(23.3 \%)$ \\
\hline $\mathrm{G} 3 / 4$ & $1(3.3 \%)$ \\
\hline \multicolumn{2}{|c|}{ Neutropenia } \\
\hline $\mathrm{G} 1$ & $4(13.3 \%)$ \\
\hline $\mathrm{G} 2$ & $6(20.0 \%)$ \\
\hline $\mathrm{G} 3 / 4$ & $5(16.6 \%)$ \\
\hline \multicolumn{2}{|l|}{ Anemia } \\
\hline $\mathrm{G} 1$ & $6(20.0 \%)$ \\
\hline $\mathrm{G} 2$ & $5(16.6 \%)$ \\
\hline $\mathrm{G} 3 / 4$ & $1(3.3 \%)$ \\
\hline \multicolumn{2}{|c|}{ Thrombocytopenia } \\
\hline $\mathrm{G} 1$ & 0 \\
\hline $\mathrm{G} 2$ & 0 \\
\hline $\mathrm{G} 3 / 4$ & 0 \\
\hline \multicolumn{2}{|c|}{ Neurotoxicity } \\
\hline $\mathrm{G} 1$ & $13(23.3 \%)$ \\
\hline $\mathrm{G} 2-4$ & 0 \\
\hline \multicolumn{2}{|l|}{ Nausea } \\
\hline G1 & $14(46.6 \%)$ \\
\hline $\mathrm{G} 2$ & $1(3.3 \%)$ \\
\hline $\mathrm{G} 3 / 4$ & 0 \\
\hline \multicolumn{2}{|l|}{ Vomiting } \\
\hline $\mathrm{G} 1$ & 0 \\
\hline $\mathrm{G} 2$ & $1(3.3 \%)$ \\
\hline $\mathrm{G} 3 / 4$ & 0 \\
\hline \multicolumn{2}{|l|}{ Alopecia } \\
\hline G1 & $1(3.3 \%)$ \\
\hline $\mathrm{G} 2$ & $6(20 \%)$ \\
\hline G3 & $23(76.6 \%)$ \\
\hline \multicolumn{2}{|c|}{ Hepatotoxicity } \\
\hline $\mathrm{G} 1$ & $2(6.6 \%)$ \\
\hline
\end{tabular}

(b)

\begin{tabular}{|c|c|}
\hline Toxicities & CCRT (13 pts) \\
\hline \multicolumn{2}{|c|}{ Leukopenia } \\
\hline G1 & 0 \\
\hline G2 & $3(23.1 \%)$ \\
\hline $\mathrm{G} 3 / 4$ & $4(30.7 \%)$ \\
\hline \multicolumn{2}{|c|}{ Neutropenia } \\
\hline G1 & $1(7.7 \%)$ \\
\hline G2 & $2(15.4 \%)$ \\
\hline $\mathrm{G} 3 / 4$ & $5(38.4 \%)$ \\
\hline \multicolumn{2}{|l|}{ Anemia } \\
\hline G1 & 0 \\
\hline G2 & $4(\%)$ \\
\hline $\mathrm{G} 3 / 4$ & 0 \\
\hline \multicolumn{2}{|c|}{ Thrombocytopenia } \\
\hline G1 & $1(7.7 \%)$ \\
\hline $\mathrm{G} 2$ & $2(15.4 \%)$ \\
\hline $\mathrm{G} 3 / 4$ & $1(7.7 \%)$ \\
\hline \multicolumn{2}{|l|}{ Nausea } \\
\hline G1 & $1(7.7 \%)$ \\
\hline G2 & $1(7.7 \%)$ \\
\hline $\mathrm{G} 3 / 4$ & 0 \\
\hline \multicolumn{2}{|l|}{ Vomiting } \\
\hline G1 & $1(7.7 \%)$ \\
\hline G2 & 0 \\
\hline $\mathrm{G} 3 / 4$ & 0 \\
\hline \multicolumn{2}{|l|}{ Diarrhea } \\
\hline G1 & $3(23.1 \%)$ \\
\hline G2 & 0 \\
\hline G3-4 & $2(15.4 \%)$ \\
\hline \multicolumn{2}{|l|}{ Cystitis } \\
\hline G1 & $4(30.8 \%)$ \\
\hline $\mathrm{G} 2$ & $1(7.7 \%)$ \\
\hline $\mathrm{G} 3 / 4$ & 0 \\
\hline
\end{tabular}

The most severe toxicities during NACT and during CCRT are reported in Table II. During NACT, G3-4 leukopenia, neutropenia and anemia occurred in $3.3 \%, 16.6 \%$, and $3.3 \%$ of the patients, respectively, whereas thrombocytopenia of any grade was never observed (Table IIa). Three patients $(10.0 \%)$ received blood transfusions and $6(20.0 \%)$ were supported with granulocyte-colony stimulating factors. Hair loss was the most frequent non-hematological toxicity: 23 women (76.6\%) had G3 alopecia. Conversely, G2 nausea, G2 vomiting and $\mathrm{G}_{1}$ hepatotoxicity (transient transaminase or bilirubin elevation) were reported in $3.3 \%, 3.3 \%$, and $6.6 \%$ of the patients, respectively. No women developed $\mathrm{G} \geq 2$ peripheral neuropathy and no life-threatening events occurred.

During CCRT, G3-4 leukopenia, neutropenia, thrombocytopenia and diarrhea developed in $30.7 \%, 38.4 \%$, $7.7 \%$ and $15.4 \%$ of the patients, respectively (Table IIb).

\section{Discussion}

CCRT plus brachytherapy is currently accepted as standard treatment for LACC (1-6). A meta-analysis of 13 trials comparing CCRT versus the same RT detected that CCRT significantly improved 5-year overall disease-free survival $(\mathrm{HR}=0.78,95 \% \mathrm{CI}=0.70-0.87), 5$-year loco-regional diseasefree survival $(\mathrm{HR}=0.76,95 \% \mathrm{CI}=0.68-0.86), \quad 5$-year metastases-free survival $(\mathrm{HR}=0.81,95 \% \mathrm{CI}=0.72-0.91)$, and 5-year OS (HR=0.81, 95\% CI=0.71-0.91) (4).

An alternative therapeutic approach using NACT before radical hysterectomy has been widely investigated, especially in Argentina, Italy, Japan, South Korea and China (12-23, 25-27). The meta-analysis of 6 randomized trials including 1078 patients with early or locally advanced disease revealed that NACT followed by radical hysterectomy significantly 
reduced the risk of progression $(\mathrm{HR}=0.75,95 \% \mathrm{CI}=0.61$ $0.93)$ and the risk of death $(\mathrm{HR}=0.77,95 \% \mathrm{CI}=0.62-0.96)$ compared to primary radical hysterectomy (31). Moreover, the meta-analysis of 5 randomized trials including 872 patients with LACC showed that chemo-surgical treatment obtained a better overall disease-free survival $(\mathrm{HR}=0.68$, $95 \% \mathrm{CI}=0.56-0.82)$, loco-regional disease-free survival ( $\mathrm{HR}=0.68,95 \% \mathrm{CI}=0.56-0.82)$, metastases-free survival $(\mathrm{HR}=0.63 ; 95 \% \mathrm{CI}=0.52-0.78)$, and $\mathrm{OS}(\mathrm{HR}=0.65,95 \%$ $\mathrm{CI}=0.53-0.80)$ compared to definitive RT, although there were some differences between trials in their design and results (8). In the Italian multicenter study, NACT arm experienced a significant better PFS and OS in patients with stage $\mathrm{Ib}_{2}$-IIb disease ( $p=0.02$ and $p=0.005$, respectively), but not in those with stage III disease (18). The recently closed EORTC randomized trial (protocol 55994) compared CDDPbased NACT plus radical surgery versus CCRT in FIGO stage $\mathrm{Ib}_{2}$-IIb cervical carcinoma. Two additional studies comparing CCRT versus NACT followed by surgery are still ongoing in India (NCT00193739) and Thailand (NCT01000415), respectively.

Different CDDP-based regimens have been used in the NACT setting $(12-30,33,34)$. Recently, dose-dense NACT with weekly TAX plus CBDCA has obtained very promising results with acceptable toxicity both in patients who underwent radical hysterectomy and in those who received definitive CCRT (35-37).

Dose-dense weekly TAX can allow a larger percentage of cancer cells to enter the vulnerable phase of their cell cycle when cytotoxic TAX concentrations are present, and moreover, the lower doses and shorter infusion times can reduce myelosuppression and other toxicities associated with standard 3-weekly schedule (41). Persistent TAX and apoptotic cells have been detected in cervical cancer tissues of patients treated with weekly schedule up to 6-7 days after the last administration (42).

Mori et al. (35) reported that NACT with TAX $\left(60 \mathrm{mg} / \mathrm{m}^{2}\right)$ plus CBDCA (AUC2) weekly for six cycles obtained a complete clinical response and partial response in 2 and 24 , respectively, of 30 patients with stage $\mathrm{Ib}_{2}$-IIIb cervical cancer, with an overall response rate of $86.7 \%$. Twenty-eight patients underwent radical hysterectomy followed by adjuvant RT in 13 cases with high-risk factors. Five-year PFS and OS were $78.6 \%$ and $81.8 \%$, respectively, in the whole series, and $79.2 \%$ and $83.1 \%$ in patients with stage $\mathrm{Ib}_{2}$-IIb disease, which were comparable with those achieved with CCRT in a similar clinical setting. In the study of Singh et al. (36), TAX $\left(60 \mathrm{mg} / \mathrm{m}^{2}\right)$ plus CBDCA (AUC2) weekly for six cycles achieved a complete response and a partial response in 2 and 17 , respectively, of 28 patients with stage IIb-IVa disease, with an overall response rate of $67.8 \%$. Twenty-four patients received CCRT, $23(82.1 \%)$ achieved a complete response, and 22 complete responders were still in complete response at a median follow-up of 12 months (range, 7 to 24 months). G3-4 neutropenia was found in $32.2 \%$ and $29 \%$ of patients, respectively, during NACT and during CCRT. Moreover, G3 nausea, vomiting and diarrhea occurred in $8 \%, 8 \%$ and $16 \%$, of the cases, respectively, during CCRT. In the phase II study of McCormack et al. (37), 46 patients with stage $\mathrm{Ib}_{2}$-IVa disease underwent NACT with TAX $\left(80 \mathrm{mg} / \mathrm{m}^{2}\right)$ and CBDCA (AUC2) weekly for six cycles followed by CCRT. Overall response rate was $70 \%$ after NACT and $85 \% 3$ months after CCRT, and OS rates were $91 \%$ at 6 months, $80 \%$ at 1 year, and $67 \%$ at both 3 and 5 years. G3-4 adverse events (mainly hematological) occurred in $20 \%$ of the patients during NACT and in $52 \%$ during CCRT.

In our preliminary experience, 30 patients underwent dosedense NACT with weekly TAX plus CBDCA followed by surgery of definitive CCRT, mainly according to tumor stage at presentation. Among the 17 patients treated with surgery, the overall clinical response rate was $82.3 \%$, similar to that reported by Mori et al. (35). Only one of these 17 patients has recurrent disease at the time of publication, but the low length of follow-up (median, 12 months) does not allow for any conclusion to be drawn about the clinical outcome of patients. The pathological examination showed an optimal response in $17.6 \%$ and a suboptimal response with intracervical residual disease in $41.2 \%$ of the surgical specimens. Histologically positive nodes, positive parametria and positive surgical margins were found in $12.5 \%, 18.7 \%$, and $6.2 \%$ of the 16 patients who underwent radical hysterectomy, respectively. In a recent Italian retrospective study, 3- weekly TAX- and CDDP- based regimens obtained an optimal pathological response and a suboptimal pathological response with intra-cervical residual disease in $19.2 \%$ and $38.1 \%$ of 333 patients with FIGO stage $\mathrm{Ib}_{2}$-IIb cervical carcinoma treated with NACT and radical hysterectomy (27). Toxicity was acceptable in agreement with literature data (35-37).

Among the 13 women who underwent definitive CCRT, FIGO stage was IIb in 7 and III-IV in 6. Seven of the 12 patients who completed treatment achieved a complete response, but 3 complete responders developed recurrent disease. These data are worse than those reported in literature $(36,37)$.

The preliminary results of this retrospective study seem to suggest that dose-dense TAX- and CBDCA-based NACT has acceptable toxicity, obtains promising response rates, and does not compromise the standard CCRT treatment. Further clinical investigation on larger series of patients with longer follow-up is strongly warranted.

The final results of the EORTC 55994 trial, together with those of the ongoing trials NCT00193739 and NCT01000415, will clarify the role of chemo-surgical treatment in patients with stage Ib2-IIb2 cervical carcinoma. Moreover, the ongoing NCT01566240 study induction chemotherapy plus chemoradiation as first line treatment for 
locally advanced cervical cancer (INTERLACE) will assess whether the induction chemotherapy with TAX $\left(80 \mathrm{mg} / \mathrm{m}^{2}\right)$ plus CBDCA (AUC2) weekly for six cycles followed by CCRT offers a clinical benefit versus CCRT alone in patients with stage $\mathrm{Ib}_{2}$-IVa cervical carcinoma.

\section{References}

1 Green J, Kirwan J, Tierney J, Symonds P, Fresco L, Williams C and Collingwood $\mathrm{M}$ : Concomitant chemotherapy and radiation therapy for cancer of the uterine cervix. Cochrane Database Syst Rev 4: CD002225, 2001.

2 Green J, Kirwan J, Tierney J, Vale C, Symonds P, Fresco L, Williams $\mathrm{C}$ and Collingwood $\mathrm{M}$ : Concomitant chemotherapy and radiation therapy for cancer of the uterine cervix. Cochrane Database Syst Rev 3: CD002225, 2005.

3 Vale C, Tierney J and Stewart L: Concomitant chemo-radiotherapy for cervical cancer: a systematic review and meta-analysis of individual patient data. Gynecol Oncol 100: 442-443, 2006.

4 Chemoradiotherapy for Cervical Cancer Meta-analysis Collaboration (CCCMAC): Reducing uncertainties about the effects of chemoradiotherapy for cervical cancer: individual patient data meta-analysis. Cochrane Database Syst Rev 1: CD008285, 2010.

5 Yang J, Yin J, Yan G, Huang D and Wang J: Postoperative chemoradiotherapy versus radiotherapy alone for cervical cancer: A systematic review and meta-analysis. J Obstet Gynaecol 36: 641-648, 2016.

6 Meng XY, Liao Y, Liu XP, Li S, Shi MJ and Zeng XT: Concurrent cisplatin-based chemoradiotherapy versus exclusive radiotherapy in high-risk cervical cancer: a meta-analysis. Onco Targets Ther 9: 1875-1888, 2016.

7 Kumar L and Gupta S: Integrating Chemotherapy in the Management of Cervical Cancer: A Critical Appraisal. Oncology 91(Suppl 1): 8-17, 2016.

8 Neoadjuvant Chemotherapy for Cervical Cancer Meta-Analysis Collaboration (NACCCMA) Collaboration. Neoadjuvant chemotherapy for locally advanced cervix cancer. Cochrane Database Syst Rev 2: CD001774, 2004.

9 Dueñas-González A, Zarbá JJ, Patel F, Alcedo JC, Beslija S, Casanova L, Pattaranutaporn $\mathrm{P}$, Hameed S, Blair JM, Barraclough $\mathrm{H}$ and Orlando $\mathrm{M}$ : Phase III, open-label, randomized study comparing concurrent gemcitabine plus cisplatin and radiation followed by adjuvant gemcitabine and cisplatin versus concurrent cisplatin and radiation in patients with stage IIB to IVA carcinoma of the cervix. J Clin Oncol 29: 1678-1685, 2011.

10 Abe A, Furumoto H, Nishimura M, Irahara M and Ikushima H: Adjuvant chemotherapy following concurrent chemoradiotherapy for uterine cervical cancer with lymphadenopathy. Oncol Lett 3: 571-576, 2012.

11 Tang J, Tang Y, Yang J and Huang S: Chemoradiation and adjuvant chemotherapy in advanced cervical adenocarcinoma. Gynecol Oncol 125: 297-302, 2012.

12 Giaroli A, Sananes C, Sardi JE, Maya AG, Bastardas ML, Snaidas L, Rueda NG, Vighi S and di Paola GR: Lymph node metastases in carcinoma of the cervix uteri: response to neoadjuvant chemotherapy and its impact on survival. Gynecol Oncol 39: 34-39, 1990.
13 Kigawa J, Minagawa Y, Ishihara H, Itamochi H, Kanamori Y and Terakawa N: The role of neoadjuvant intraarterial infusion chemotherapy with cisplatin and bleomycin for locally advanced cervical cancer. Am J Clin Oncol 19: 255-259,1996.

14 Sardi JE,Giaroli A, Sananes C, Ferreira M, Soderini A, Bermudez A, Snaidas L, Vighi S, Gomez Rueda N and di Paola G: Long-term follow-up of the first randomized trial using neoadjuvant chemotherapy in stage Ib squamous carcinoma of the cervix: the final results. Gynecol Oncol 67: 61-69, 1997.

15 Zanetta G, Lissoni A, Pellegrino A, Sessa C, Colombo N, GueliAlletti D and Mangioni C: Neoadjuvant chemotherapy with cisplatin, ifosfamide and paclitaxel for locally advanced squamous-cell cervical cancer. Ann Oncol 9: 977-980, 1998.

16 Sananes C, Giaroli A, Soderini A, Guardado N, Snaidas L, Bermudez A, Ferreira M, di Paola G and Sardi J: Neoadjuvant chemotherapy followed by radical hysterectomy and postoperative adjuvant chemotherapy in the treatment of carcinoma of the cervix uteri: long-term follow-up of a pilot study. Eur J Gynaecol Oncol 19: 368-173,1998.

17 Chang TC, Lai CH, Hong JH, Hsueh S, Huang KG, Chou HH, Tseng CJ, Tsai CS, Chang JT, Lin CT, Chang HH, Chao PJ, Ng KK, Tang SG and Soong YK: Randomized trial of neoadjuvant cisplatin, vincristine, bleomycin, and radical hysterectomy versus radiation therapy for bulky stage IB and IIA cervical cancer. J Clin Oncol 18: 1740-1747, 2000.

18 Benedetti-Panici P, Greggi S,Colombo A, Amoroso M, Smaniotto D, Giannarelli D, Amunni G, Raspagliesi F, Zola P, Mangioni $\mathrm{C}$ and Landoni F: Neoadjuvant chemotherapy and radical surgery versus exclusive radiotherapy in locally advanced squamous cell cervical cancer: results from the Italian multicenter randomized study. J Clin Oncol 20: 179-188, 2002.

19 Huang HJ, Chang TC, Hong JH, Tseng CJ, Chou HH, Huang $\mathrm{KG}$ and Lai $\mathrm{CH}$ : Prognostic value of age and histologic type in neoadjuvant chemotherapy plus radical surgery for bulky ( $>4$ $\mathrm{cm})$ stage IB and IIA cervical carcinoma. Int J Gynecol Cancer 13: 204-211, 2003.

20 Napolitano U, Imperato F, Mossa B, Framarino ML, Marziani R and Marzetti L: The role of neoadjuvant chemotherapy for squamous cell cervical cancer (Ib-IIIb): a long-term randomized trial. Eur J Gynaecol Oncol 24: 51-59, 2003.

21 Buda A, Fossati R, Colombo N, Fei F, Floriani I,Gueli Alletti D, Katsaros D, Landoni F, Lissoni A, Malzoni C, Sartori E, Scollo P, Torri V, Zola P and Mangioni C: Randomized trial of neoadjuvant chemotherapy comparing paclitaxel, ifosfamide, and cisplatin with ifosfamide and cisplatin followed by radical surgery in patients with locally advanced squamous cell cervical carcinoma: the SNAP01 (Studio Neo-Adjuvante Portio) Italian Collaborative Study. J Clin Oncol 23: 4137-4145, 2005.

22 Cai HB, Chen HZ and Yin HH: Randomized study of preoperative chemotherapy versus primary surgery for stage IB cervical cancer. J Obstet Gynaecol Res 3: 2315-2323, 2006.

23 Katsumata N, Yoshikawa H, Kobayashi H, Saito T, Kuzuya K, Nakanishi T, Yasugi T, Yaegashi N, Yokota H, Kodama S, Mizunoe T, Hiura M, Kasamatsu T, Shibata T and Kamura T: Phase III randomised controlled trial of neoadjuvant chemotherapy plus radical surgery vs radical surgery alone for stages IB2, IIA2, and IIB cervical cancer: a Japan Clinical Oncology Group trial (JCOG0102). Br J Cancer 108: 1957-1963, 2013.

24 Eddy GL, Bundy BN, Creasman WT, Spirtos NM, Mannel RS, Hannigan E and O'Connor D: Treatment of ("bulky") stage IB 
cervical cancer with or without neoadjuvant vincristine and cisplatin prior to radical hysterectomy and pelvic/para-aortic lymphadenectomy: a phase III trial of the gynecologic oncology group. Gynecol Oncol 106: 362-369, 2007.

25 Chen $\mathrm{H}$, Liang $\mathrm{C}$, Zhang L and Huang S and Wu X: Clinical efficacy of modified preoperative neoadjuvant chemotherapy in the treatment of locally advanced (stage IB2 to IIB) cervical cancer: randomized study. Gynecol Oncol 110: 308-315, 2008.

26 Lissoni AA, Colombo N, Pellegrino A, Parma G, Zola P, Katsaros D, Chiari S, Buda A, Landoni F, Peiretti M, Dell' anna T, Fruscio R, Signorelli M, Grassi R, Floriani I, Fossati R, Torri V and Rulli E: A phase II, randomized trial of neo-adjuvant chemotherapy comparing a three-drug combination of paclitaxel, ifosfamide, and cisplatin (TIP) versus paclitaxel and cisplatin (TP) followed by radical surgery in patients with locally advanced squamous cell cervical carcinoma: the Snap-02 Italian Collaborative Study. Ann Oncol 20: 660-665, 2009.

27 Gadducci A, Sartori E, Maggino T, Zola P, Cosio S, Zizioli V, Lapresa M, Piovano E and Landoni F: Pathological response on surgical samples is an independent prognostic variable for patients with Stage Ib2-IIb cervical cancer treated with neoadjuvant chemotherapy and radical hysterectomy: an Italian multicenter retrospective study (CTF Study). Gynecol Oncol 131: 640-644, 2013.

28 Lapresa M, Parma G, Portuesi R and Colombo N: Neoadjuvant chemotherapy in cervical cancer: an update. Expert Rev Anticancer Ther 15: 1171-1181, 2015.

29 Shoji T, Takatori E, Furutake Y, Takada A, Nagasawa T, Omi H, Kagabu M, Honda T, Miura F, Takeuchi S, Kumagai S, Yoshizaki A, Sato A and Sugiyama T: Phase II clinical study of neoadjuvant chemotherapy with $\mathrm{CDDP} / \mathrm{CPT}-11$ regimen in combination with radical hysterectomy for cervical cancer with a bulky mass. Int J Clin Oncol 21: 1120-1127, 2016.

30 Rydzewska L, Tierney J, Vale CL and Symonds PR: Neoadjuvant chemotherapy plus surgery versus surgery for cervical cancer. Cochrane Database Syst Rev 12: CD007406, 2012.

31 Zanaboni F, Grijuela B, Giudici S, Cormio G, Babilonti L, Ghezzi F, Giorda G, Scambia G, Franchi M, Lorusso M, Ditto A, Lorusso D and Raspagliesi F: Weekly topotecan and cisplatin (TOPOCIS) as neo-adjuvant chemotherapy for locally-advanced squamous cervical carcinoma: Results of a phase II multicentric study. Eur J Cancer 49: 1065-1072, 2013.

32 Kitagawa R, Katsumata N, Shibata T, Kamura T, Kasamatsu T, Nakanishi T, Nishimura S, Ushijima K, Takano M, Satoh T and Yoshikawa H: Paclitaxel plus carboplatin versus paclitaxel plus cisplatin in metastatic or recurrent cervical cancer: the openlabel randomized phase III trial JCOG0505. J Clin Oncol 33: 2129-2135, 2015.

33 Dueñas-Gonzalez A, López-Graniel C, González-Enciso A, Cetina L,Rivera L,Mariscal I, Montalvo G, Gómez E,de la Garza J, Chanona G and Mohar A: A phase II study of multimodality treatment for locally advanced cervical cancer: neoadjuvant carboplatin and paclitaxel followed by radical hysterectomy and adjuvant cisplatin chemoradiation. Ann Oncol 14: 1278-1284, 2003 .
34 Angioli R, Plotti F, Luvero D, Aloisi A, Guzzo F, Capriglione S, Terranova C, De Cicco Nardone $\mathrm{C}$ and Benedetti-Panici P: Feasibility and safety of carboplatin plus paclitaxel as neoadjuvant chemotherapy for locally advanced cervical cancer: a pilot study. Tumour Biol 35: 2741-2746, 2014.

35 Mori T, Hosokawa K, Sawada M, Kuroboshi H, Tatsumi H, Koshiba H, Okubo T and Kitawaki J: Neoadjuvant weekly carboplatin and paclitaxel followed by radical hysterectomy for locally advanced cervical cancer: long-term results. Int $\mathrm{J}$ Gynecol Cancer 20: 611-616, 2010.

36 Singh RB, Chander S, Mohanti BK, Pathy S, Kumar S, Bhatla N, Thulkar S, Vishnubhatla S and Kumar L: Neoadjuvant chemotherapy with weekly paclitaxel and carboplatin followed by chemoradiation in locally advanced cervical carcinoma: a pilot study. Gynecol Oncol 129: 124-128, 2013.

37 McCormack M, Kadalayil L, Hackshaw A, Hall-Craggs MA, Symonds RP, Warwick V, Simonds H, Fernando I, Hammond M, James L, Feeney A and Ledermann JA: A phase II study of weekly neoadjuvant chemotherapy followed by radical chemoradiation for locally advanced cervical cancer. Br J Cancer 108: 2464-2469, 2013.

38 Eisenhauer EA, Therasse P, Bogaerts J, Schwartz LH, Sargent D, Ford R, Dancey J, Arbuck S, Gwyther S, Mooney M, Rubinstein L, Shankar L, Dodd L, Kaplan R, Lacombe D and Verweij J: New response evaluation criteria in solid tumours: revised RECIST guideline (version1.1). Eur J Cancer 45: 228$247,2009$.

39 Viswanathan AN, Beriwal S, De Los Santos JF, Demanes DJ, Gaffney D, Hansen J, Jones E, Kirisits C, Thomadsen B and Erickson B: American Brachytherapy Society consensus guidelines for locally advanced carcinoma of the cervix. Part II: high-dose-rate brachytherapy. Brachytherapy 11: 47-52, 2012.

40 Cox JD, Stetz J and Pajak TF: Toxicity criteria of the Radiation Therapy Oncology Group (RTOG) and the European Organization for Research and Treatment of Cancer (EORTC) Int J Radiat Oncol Biol Phys 31: 1341-1346, 1995.

41 Thomas H and Rosenberg P: Role of weekly paclitaxel in the treatment of advanced ovarian cancer. Crit Rev Oncol Hematol 44(Suppl): S43-51, 2002.

42 Mori T, Kinoshita Y, Watanabe A, Yamaguchi T, Hosokawa K and Honjo H: Retention of paclitaxel in cancer cells for 1 week in vivo and in vitro. Cancer Chemother Pharmacol 58: 61656172,2006
Received February 7, 2017

Revised February 24, 2017

Accepted February 24, 2017 